\title{
The Inaugural National Leadership Education Research Agenda: A New Direction for the Field
}

\author{
Anthony C. Andenoro, Ph.D. \\ Assistant Professor of Leadership Education \\ Agricultural Education \& Communication \\ University of Florida \\ Gainesville, FL \\ andenoro@ufl.edu
}

\begin{abstract}
This commentary details the process aimed at developing the Inaugural National Leadership Education Research Agenda. The goal of the project is to create a guiding document to assist in further defining Leadership Education as a discipline and provide directional research priorities for that discipline. The commentary provides a foundational understanding and creates transparency for the process in an effort to solicit collaborative partnerships and dialogue that will ultimately provide more holistic research priorities and enhanced opportunities for scholarship within Leadership Education.
\end{abstract}

\section{Introduction}

In the 2007, the first iteration of the National Research Agenda for Agricultural Education and Communication created a foundation for communicating research priorities to stakeholders along with the "development, acceptance, and evaluation of creative solutions in agriculture and natural resources" (Osborne, n.d., p.2). However, the idea actually stemmed from an interaction that took place over a year prior to that in Washington DC. A group of well-established agricultural educators met to discuss a variety of legislative items impacting the field of Agriculture and more specifically Agricultural Education. During one of the meetings a lobbyist was present to collect perspectives and answer potential questions that the group might have. During the conversation the lobbyist noted that there was tremendous opportunity for this group considering what he had heard and observed. He asked them for a document that he could take to Capitol Hill later that afternoon that could provide perspective to the legislative decision makers. As the group looked at one another, they realized two things. First, that they did not have a document that provided the information that the lobbyist had 
asked for. This was concerning for them. And second, that they needed to construct a document that could serve in this capacity with the potential to create tremendous opportunities for the field of Agricultural Education in the future. The group vowed that they would not allow an opportunity like this to pass and engaged in a collaborative process to develop a research agenda. The process yielded a document, which created innovative and positive direction for the field of Agricultural Education and Communication. The second iteration of this document was released in 2011 demonstrating progressive thinking and furthering the commitment to "inspiring the human dimension of global food and agricultural systems" (Doerfert, 2011, p.5).

This story provides context and perspective to the field of Leadership Education. In 2011, the Association of Leadership Educators with respect to this idea initiated the task of building a National Leadership Education Research Agenda. This commentary details the process for that ongoing effort.

\section{Justification}

When one attempts to define the merits of a discipline, he or she will normally examine the uniqueness of the body of knowledge represented within that discipline. However, this has been a difficult proposition for the field of Leadership Education historically. Primarily the difficulty to define the field lies in the interdisciplinary nature of leadership. Consider that at most universities, one will find some form of leadership education being taught in Colleges of Business, Agriculture, Engineering, Education, Liberal Arts, along with a large contingent of Student Affairs departments. This poses challenges for those who are attempting to define what Leadership Education is as a discipline, but it also creates an incredible opportunity. Through the diversity of perspectives contained in various academic and co-curricular departments, Leadership Education as a discipline finds broad trans-disciplinary application. The development of the National Leadership Education Research Agenda addresses that broad application in a manageable and strategic fashion. As the agenda guides the scholarship of Leadership Education as a discipline, it also defines it as a discipline.

Another challenge facing the field of Leadership Education is the general lack of research priorities aimed at guiding the scholarship within field. Although this creates opportunities for diverse publications with broad applications, it decreases the applied nature of the scholarship. Primarily, researchers within Leadership Education continue to ask and attempt to answer the fundamental leadership question: what makes an effective leader? This is accompanied by the tangible connections to decision-making, ethics, morality, and organizational culture. However, the more important questions facing the field of Leadership Education 
are who has changed because of this research and how will the research that we do impact those we serve? The National Leadership Education Research Agenda provides the underpinning for increasing the applied nature of the scholarship guiding the development of future leaders and managers through higher education.

\section{The Process}

"To know where we are going with leadership [education] research, we must know where we are, and where we have been-we must look backward and forward at the same time" (Hunt \& Dodge, 2000, p. 453). The preceding quotation identifies the vastness associated with the challenge of defining the field of Leadership Education. Due to this, it was imperative to provide parameters to the direction that will shape the scholarship within the field. For the first six months of the process, discussions took place across disciplines exploring the vast array of discussions that had taken place concerning the scholarship of Leadership Education over the past decade. These discussions provided critical perspectives relating to the establishment of parameters that would guide the development process. Through a synthesis of the materials and perspectives gained through the discussions one question emerged:

- What are the fundamental problems and issues within the broad context of Leadership Education that should be addressed at the higher education level through research in the next five years?

This question is essential for achieving the two overarching goals of the agenda (a) to provide research priorities that can guide applied scholarship contributing to the development of future leaders and managers through higher education and (b) to provide key elements that further define Leadership Education as a discipline. Considering this, the following seven-phase process was initiated in May 2012.

Phase 1: Synthesis of Past Perspective - Previously, it was noted that a large number of discussions were held to solicit perspectives and develop parameters for the National Leadership Education Research Agenda. However, the discussions were also conducted to encourage collaboration. The collaborative nature of these discussions forced stakeholders to consider varying viewpoints, but it also reduced silos, established partnerships, and increased the likelihood of diffusion and adoption of this document. Organizations that participated in the conversations were the American Association of Agricultural Education (AAAE), American College Personnel Association (ACPA), Association of College Unions International (ACUI), Center for Creative Leadership (CCL), International 
Leadership Association (ILA), National Association for Campus Activities (NACA), National Association of Student Personnel Administrators (NASPA), and National Clearinghouse for Leadership Programs (NCLP).

Considerable documentation also was collected as a result of these discussions. Several white papers (Petrie, 2011; Doerfert, 2011; Osborne, n.d.), transcripts, and minutes from organizational meetings addressing similar initiatives, as well as other seminal research (Sowcik, 2012; Gardner, Lowe, Moss, Mahoney, \& Cogliser, 2010; Avolio, Wallumbwa, \& Weber, 2009; Rich \& Mengel, 2009; Brungardt, Greenleaf, Brungardt, \& Arensdorf, 2006; Bryman, 2004; Townsend, 2002; Lowe \& Gardner, 2001; Conger, 1998; Parry, 1998; Insch, Moore, \& Murphy, 1997; Brungardt, 1996; Bresnen, 1995; Fleishman, Zaccaro, \& Mumford, 1991) done addressing the direction of leadership education research were examined.

The documents detailing past discussions, perspectives from various organizations charged with addressing the idea of a research trajectory for Leadership Education, and the relevant literature were explored via a content analysis allowing for themes to emerge. These themes will provide the foundation for the future phases and ultimately, the development of the agenda.

Phase 2: Understanding Recommendations for Future Research in the Field Graduate students at the University of Florida were charged with exploring the recommendations for future research listed within articles published from 20102012 in the Journal of College Student Development, Journal of Leadership \& Organizational Studies, Journal of Leadership Education, Journal of Leadership Studies, and Leadership Quarterly. These journals were selected based on their reputational excellence and alignment with Leadership Education in a higher education context. A content analysis was performed identifying consistent themes. The themes provided timely perspectives and enhanced triangulation.

Phase 3: Leadership Education Summit - There are several engaged academicians conducting innovative and groundbreaking research in Leadership Education from an interdisciplinary perspective. Their perspectives are critical to this process and many of them will be collected via focus group discussions at a location and time to be determined. The documents, perspectives, and themes stemming from Phases 1 and 2 will provide a foundation and increased direction for the focus groups discussions. The respondents were purposively sampled for their ability to provide typical and divergent data and insights to capture the essence of the context; therefore, as a result invitations were extended to eight individuals that represented various organizations and disciplines (i.e., business, agricultural education, student affairs administration, etc.). Data will be analyzed using the 
constant comparative method (Glaser \& Strauss, 1967) and will provide insight into the establishment of the research priorities.

Phase 4: Document Development - The previous three phases and the data stemming from them will provide the foundation for the development of a draft document encapsulating the agenda. Triangulation will ensure that trustworthiness can be maintained and that varying divergent perspectives are collected about different perspectives (Erlandson, Harris, Skipper, \& Allen, 1993).

Phase 5: Confirmation - The document established through the previous phases will be vetted by preeminent scholars in the field of Leadership Education. Their perspectives will address opportunities for revision and create a holistic document grounded in the past and aimed at the future of Leadership Education as a discipline. Five scholars were invited to participate in this process based on their venerable engagement in and outstanding contributions to the field of Leadership Education.

Phase 6: Revision - Revisions will be made based on perspectives gleaned from Step 5. A final draft will be developed and formatted for dissemination.

Phase 7: Dissemination - The agenda will be presented at the 2013 Association of Leadership Educators Conference in New Orleans, LA. Contributors will be asked to develop manuscripts addressing their perspectives of the agenda with respect to their area of Leadership Education (i.e., Education, Business, Agricultural Education, etc.) for a special issue of the Journal of Leadership Education.

\section{Conclusion}

The people of the United States face the perspective of a future riddled with an impending fiscal cliff, labor crisis, climate change, countless examples of questionable ethics in the private sector, and other considerable hardships. These uncertain times call for strategic and innovative measures to stem the tide of adversity. Quality leadership will be paramount as the nation attempts to set the foundation for the future. Leadership Education creates a foundation for promoting social justice and the potential to meet the needs of these trying times. It assists in the attempt to develop perspectives that will be critical for the establishment of community resiliency and collective consciousness of these and similar issues.

As a discipline Leadership Education stands on the precipice of this uncertain future with the ability to significantly impact the nations' capacity to navigate troubled times. The responsibility to develop strong leaders grounded in the 
values, perspectives, and competencies essential for addressing these issues will fall to those serving as Leadership Educators. The National Leadership Education Research Agenda provides direction for this responsibility. It will establish a plan for scholarship that will lead to the development of enhanced educational opportunities for those served through Leadership Education. The ultimate goal of this effort is to provide a research trajectory through a coordinated, purposive, credible, and strategic process that will ultimately lead to significant contributions within the field of Leadership Education. The agenda will provide perspective to leadership educators and further define the field. This is not only timely; it is necessary. 


\section{References}

Avolio, B. J., Wallumbwa, F. O., \& Weber, T. J. (2009). Leadership: Current theories, research, and future directions. The Annual Review of Psychology, 60, 421-449.

Bresnen, M. J. (1995). All things to all people? Perceptions, attributions, and constructions of leadership. Leadership Quarterly, 6(4), 495-513.

Brungardt, C., Greenleaf, J., Brungardt, C., \& Arensdorf, J. (2006). Majoring in leadership: A review of undergraduate leadership degree programs. Journal of Leadership Education, 5(1), 4-25.

Brungardt, C. (1996). The making of leaders: A review of the research in leadership development and education. The Journal of Leadership and Organizational Studies, 3(3), 81-95.

Bryman, A. (2004). Qualitative research on leadership: A critical but appreciative review. Leadership Quarterly, 15, 729-769.

Conger, J. A. (1998). Qualitative research as the cornerstone methodology for understanding leadership. Leadership Quarterly, 9(l), 107-121.

Doerfert, D. L. (Ed.) (2011). National research agenda: American Association for Agricultural Education's research priority areas for 2011-2015. Lubbock, TX: Texas Tech University, Department of Agricultural Educations and Communications.

Erlandson, D. A., Harris, E. L., Skipper, B. L., \& Allen, S. D. (1993). Doing Naturalistic inquiry: A guide to methods. Newbury Park, CA: Sage Publications.

Fleishman, E. A., Zaccaro, S. J., \& Mumford, M. D. (1991). Individual differences and leadership: An overview. Leadership Quarterly, 2(4), 237-243.

Gardner, W. L., Lowe, K. B., Moss, T. W., Mahoney, K. T., \& Cogliser, C. C. (2010). Scholarly leadership of the study of leadership: A review of The Leadership Quarterly's second decade, 2000-2009. Leadership Quarterly, 21, 922-958. 
Glaser, B. G., \& Strauss, A. L. (1967). The discovery of grounded theory. Hawthorne, NY: Aldine.

Hunt, J. G., \& Dodge, G. E. (2000). Leadership déjà vu all over again. Leadership Quarterly, 11, 435-458.

Insch, G. S., Moore, J. E., \& Murphy, L. D. (1997). Content analysis in leadership research: Examples, procedures and suggestions for future use. Leadership Quarterly, 8(l), 1-25.

Lowe, K. B., \& Gardner, W. L. (2001). Ten years of Leadership Quarterly: Contributions and challenges for the future. Leadership Quarterly, 11, 459-514.

Osborne, E.W. (Ed.) (n.d.). National research agenda: Agricultural education And communication, 2007-2010. Gainesville, FL: University of Florida, Department of Agricultural Education and Communication.

Parry, K. W. (1998). Grounded theory and social process: A new direction for Leadership research. Leadership Quarterly, $9(l), 85.105$.

Petrie, N. (2011). Future trends in leadership development. A white paper. Colorado Spring, CO: The Center for Creative Leadership.

Rich, S. W., \& Mengel, T. (2009). Guiding Questions: Guidelines for Leadership Education Programs. Journal of Leadership Education, 8(1). 216-227.

Sowcik, M. (2012). A Review and Critique of Guiding Questions: Guidelines for Leadership Education Programs. Journal of Leadership Education, 11(2), 192-213.

Townsend, C. D. (2002). Leadership Education: Fantasy or Reality? Journal of Leadership Education, 1(1), 35-40. 


\section{Author Biography}

Anthony C. Andenoro currently serves as an Assistant Professor of Leadership Education within the Department of Agricultural Education and Communication at the University of Florida and is the President for the Association of Leadership Educators. His research interests include the development of creativity and intelligence in leadership, using storytelling as a vehicle for the development of self-awareness, the development of emotionally intelligent instruction and instructors, and the globalization leadership curricula. Dr. Andenoro earned a B.A. in Communication from the University of Toledo, a M.S. in Educational Administration from Texas A\&M University, and a Ph.D. in Agricultural Education with an emphasis in Leadership Education from Texas A\&M University. 